\title{
Esplenomegalia asociada a muertes por ahorcadura. Enero a diciembre 2011
}

Karina Pariona, Elizabeth Carrera, Rosario Lira, Shérmany Aronés, Mario Castro, Judith Maguiña

Instituto de Medicina Legal, Ministerio Público, e Instituto de Patología, UNMSM

\begin{abstract}
Introducción: La esplenomegalia se produce por múltiples causas, siendo indicador de compromiso patológico sistémico; el peso promedio es variable, dependiendo de factores diversos asociados, entre ellos, patologías previas, constitución, trastornos inflamatorios, neoplásicos, inmunológicos, metabólicos; el peso considerado dentro del promedio normal es de $80 \mathrm{~g}$, en individuos de $70 \mathrm{~kg}$ con $170 \mathrm{~cm}$ de estatura.
\end{abstract}

Objetivos: Determinar el promedio de pesos de bazos hallados en cadáveres por ahorcadura.

Diseño: Cuantitativo descriptivo y transversal.

Institución: Instituto de Medicina Legal, Ministerio Público, e Instituto de Patología, UNMSM.

Material de estudio: Protocolos de necropsias de muertes violentas por ahorcadura.

Intervenciones: Medicolegales, por denuncia al Ministerio Público por violencia.

Principales medidas de resultados: Medidas, tendencia central, porcentual.

Resultados: Se seleccionó 89 casos de ahorcadura, de 4500 necropsias, en el año 2011, encontrando la mayor

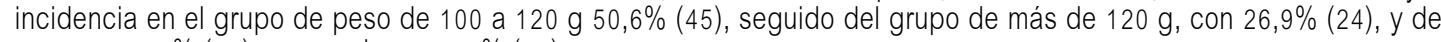

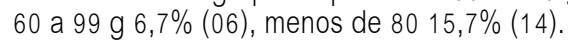

Conclusiones: Existió esplenomegalia asociada a muertes suicidas por ahorcadura en $77,5 \%$ (69), que indica proceso patológico sistémico no diagnosticado.

Palabras clave: Esplenomegalia, suicidio, ahorcadura.

\section{Factores asociados al daño múltiple de órganos, en Morgue Central de Lima, enero a diciembre 2010}

Mary Lapiz, Rosa Carrera, Kelly Casana, Shérmany Aronés Instituto de Medicina Legal, Ministerio Público, e Instituto de Patología, UNMSM

Introducción: Las confusiones generadas por las denominaciones daño múltiple de órganos (DOM-FOM) en las autopsias de fallecidos con diagnóstico de Síndrome de Disfunción Múltiple de Órganos, no identifican como daño múltiple de órganos (DMO) a las lesiones diagnosticadas, sin diferenciarse daño orgánico del funcional. Entre los factores causales conducentes a estado crítico se menciona: infecciones, quemaduras, traumatismos, cáncer, choque, intoxicaciones, etc.

Objetivos: Determinar los factores asociados al DMO.

Diseño: Descriptivo, retrospectivo, transversal.

Institución: Instituto de Medicina Legal, Ministerio Público, e Instituto de Patología, UNMSM.

Material de estudio: Protocolos de necropsia.

Intervenciones: Revisión de protocolos de necropsia.

Principales medidas de resultados: Medidas de tendencia central, frecuencias.

Resultados: El DMO representó 4,9\% (224) de las causas de muerte, con mayor frecuencia en sexo masculino $62,9 \%$ (141), grupo etario 61 a 70 años. Databa de la muerte 12 a 24 horas en 45\%; meses junio-agosto en 28\%. El diagnóstico final de causa de muerte más frecuente fue falla orgánica múltiple/falla multiorgánica, disfunción múltiple de órganos/ multiorgánica; las causa básicas fueron: infecciones, traumatismos, quemaduras y neoplasias; de procedencia institución de salud $87 \%$.

Conclusiones: No se consignó DMO como diagnóstico; 50,4\% (113) no registró causa básica de muerte; los principales factores asociados fueron las infecciones, sexo masculino, adulto mayor y procedencia hospitalaria, que guardaba relación con estudios previos.

Palabras clave: Daño múltiple de órganos, falla orgánica múltiple, necropsia. 